The Perceived Stability and Biological Basis of Religious Beliefs, Factual Beliefs, and Opinions

Word Count: 9,540

(C) 2016. This manuscript version is made available under the Elsevier user license http://www.elsevier.com/open-access/userlicense/1.0/ 


\begin{abstract}
Prior work shows that children view group membership and psychological traits in essentialist terms, perceiving them to be both biologically determined and stable across time. To what extent might individuals view mental states such as beliefs similarly? Given that beliefs are often based on experience and can change across time, one hypothesis is that beliefs on the whole do not elicit essentialism. An alternative hypothesis, however, is that some beliefs may be perceived as inherited and stable over time - characteristics associated with essentialism. In three studies, we examined two aspects of psychological essentialism regarding three different types of beliefs (religious beliefs, factual beliefs, opinions) in 8- to 10-year-olds and adults, asking whether beliefs are seen as (1) biologically based and/or (2) stable across time. Both children and adults distinguished among belief types when considering biology: opinions were perceived to be more rooted in biology than other beliefs. By contrast, fewer consistent differences emerged when children and adults considered stability. For example, both children and adults perceived opinions and factual beliefs to be equally changeable. Finally, although children typically perceived beliefs to be more rooted in biology than did adults, more specific patterns across belief types (e.g., perceiving opinions to be more rooted in biology than religious beliefs) remained relatively stable across age groups. Thus, development and social learning may play a larger role in perceptions of the biological component of essentialism than in judgments of particular beliefs. We discuss implications for literatures on essentialism, religious cognition, and social cognitive development.
\end{abstract}

Keywords: essentialism; religious cognition; social cognitive development 


\section{The Perceived Stability and Biological Basis of Religious Beliefs, Factual Beliefs, and}

\section{Opinions}

Psychological essentialism — the notion that internal characteristics or "essences" give rise to surface features of agents and objects (Gelman, 2003; Medin \& Ortony, 1989) — is an important aspect of human cognition. Emerging early in development (Gelman, 2003; Gil-White, 2001; Rhodes, Leslie, \& Tworek, 2012; Taborda-Osorio \& Cheries, under review) and persisting through adulthood (Dar-Nimrod \& Heine, 2011; Haslam, Bastian, \& Bissett, 2004), psychological essentialism may stem in part from individuals' propensity to reference inherent properties when explaining why people or objects are the way they are (Cimpian \& Salomon, 2014). Psychological essentialism has been linked with a number of attitudes and behaviors with important social consequences, including stereotyping of and prejudice toward minority groups (Haslam \& Levy, 2006; Jayaratne et al., 2006; Williams \& Eberhardt, 2008), punitiveness (DarNimrod, Heine, Cheung, \& Schaller, 2011; Kraus \& Keltner, 2013; Monterosso, Royzman, \& Schwartz, 2005), and social perception (e.g., remembering and categorizing racially ambiguous people; Chao, Hong, \& Chiiu, 2013; Gaither et al., 2014; Ho, Roberts, \& Gelman, 2015). Within psychology, "essences” have been largely conceptualized as characteristics that are innate, unchanging, richly predictive, and/or biologically based (Dar-Nimrod \& Heine, 2011; Diesendruck, Birnbaum, Deeb, Segall, 2013; Gelman, Heyman, \& Legare, 2007; Haslam, Rothschild, \& Ernst, 2000; Taylor, Rhodes, \& Gelman, 2009; Waxman, Medin, \& Ross, 2007). Psychologists have focused on studying psychological essentialism (laypeople's judgments of the extent to which particular groups and characteristics have stable, biologically based essences) and have avoided making claims about whether or not such essences actually exist. However, for 
brevity, we subsequently refer to work on "essentialism" rather than specifying "psychological essentialism" in each case.

\section{The Importance of Investigating Essentialism across Development}

To date, psychologists have largely investigated essentialism of two types of entities: groups (both natural kinds and social kinds) and psychological characteristics. For each of these entities, essentialist reasoning emerges early in development. Elementary school children judge that ethnicity is inherited from one's parents (Diesendruck et al., 2013), that gender-linked attributes are innate (Taylor et al., 2009), and that species-based properties such as mooing versus oinking depend on an animal's birth parents rather than adoptive parents (Sousa, Atran, \& Medin, 2002; based on Gelman \& Wellman, 1991). Elementary school children also judge that people who have different psychological characteristics (e.g., shy versus not shy) have different brains (Gelman et al., 2007). Relatedly, children in this age group can represent a number of psychological characteristics — including intelligence, morality, and shyness — as unchanging and innate (Erdley \& Dweck, 1993; Heyman \& Dweck, 1998).

Prior work has shown that essentialism regarding groups and psychological characteristics decreases with age (Gelman et al., 2007; Heyman \& Gelman, 2000; Taylor, 1996; Taylor et al., 2009). This developmental shift may indicate that people, by default, make essentialist judgments when forming category-based judgments in childhood and only later, in adulthood, develop the capacity for more considered judgments that accommodate environmental factors (Eidson \& Coley, 2014; Gelman et al., 2007). Whether this developmental pattern applies to beliefs in addition to natural kinds, social categories, and psychological characteristics is an open question that the current work sought to answer. 
The present research explored developmental differences by testing 8- to 10-year-old children and adults within the same paradigm. We tested children between 8 and 10 years because they are capable of reasoning about religious beliefs (Heiphetz, Spelke, Harris, \& Banaji, 2013, 2014), which form a central component of the present research. Furthermore, 8- to 10-year-olds have sufficient scientific knowledge to answer questions about the biological component of essentialism (Gelman et al., 2007).

If beliefs elicit the same developmental pattern as the characteristics studied in prior work on essentialism, children should report more essentialism than adults. This finding would suggest that the tendency to apply an essentialist framework extends beyond the phenomena studied in the past to the new domain of beliefs. Thus, such a finding would highlight the pervasive nature of essentialist judgments.

The Importance of Investigating Essentialism Regarding Religious Beliefs, Factual Beliefs, and Opinions

The current work examined the extent to which children and adults might perceive beliefs, which have not been studied previously in the psychological literature on essentialism, in essentialist terms. That is, to what extent might children and adults perceive beliefs to be (a) rooted in biology and (b) stable across time? Answering these questions extends the literature on essentialism into a new domain and therefore provides greater insight into the scope and extent of essentialist judgments, including whether they function similarly or differently across domains. Additionally, much prior work on essentialism has focused on attributes that are linked to categories (e.g., animal kinds, gender, race), whereas beliefs vary across individuals within a category. It is thus of great interest to test whether essentialist beliefs extend to such attributes. For a discussion of similarities and differences between beliefs and other characteristics typically 
studied in the essentialism literature (e.g., traits such as shyness and intelligence), see General Discussion.

At first blush, the idea that beliefs elicit essentialism may be implausible. Rather than arising from internal sources such as genes, beliefs are often acquired from others. Furthermore, rather than remaining stable over time, beliefs often change. Nevertheless, there are three key reasons to suggest that individuals - especially children - may view some beliefs in essentialist terms. First, beliefs are often perceived as internal properties that reside in someone's brain. For example, children in elementary school understand that the brain is necessary for thinking (i.e., for holding beliefs, Gottfried, Gelman, \& Schultz, 1999) and report that thoughts are located in the brain (i.e., that if a human brain were moved into a pig's body, the pig would think differently, Johnson, 1990). Second, children may observe that some beliefs-for example, religious beliefs - are often passed down from parents to children, much like inherited characteristics (Barro, Hwang, \& McCleary, 2010). Third, certain beliefs may be viewed as being beyond one's control and not a matter of personal choice. For example, people cannot simply choose to believe that broccoli is tasty when they do not like it or to believe that tag is the best game when they do not enjoy playing it (for related work, see Chernyak, Kushnir, Sullivan, \& Wang, 2013). Importantly, as prior work with adults has found, the less that beliefs are thought to be chosen, the more they are thought to be caused by biological essences (Jayaratne et al., 2009). Thus, we tested the novel prediction that individuals perceive some beliefs in essentialist terms.

For two reasons, we began our investigation with religious beliefs. First, religious beliefs are an important, yet under-studied, aspect of identity. Although children may not understand the nuances of theology, they endorse the existence of a number of religious phenomena, including 
God (Guerrero, Enesco, \& Harris, 2010; Shtulman, 2008), souls (Richert \& Harris, 2006), and the afterlife (Bering, Blasi, \& Bjorklund, 2005). People judge each other on the basis of their religious beliefs, inferring that religious in-group members are particularly moral whereas atheists are particularly immoral (Gervais, Shariff, \& Norenzayan, 2011; Heiphetz, Spelke, \& Banaji, 2014). Yet how people conceptualize religious beliefs remains unclear, and the current work sought to shed light on this question.

Second, prior work has shown that adults view some religious categories in essentialist terms (Segev, Bergman, \& Diesendruck, 2012; Toosi \& Ambady, 2011). Although the link between religious beliefs and religious categories is not perfect, particular beliefs are nevertheless frequently associated with particular religious groups. For example, knowing that someone believes that she can please God by avoiding shellfish and resting on Shabbat affords inferences about that individual's religious category. Some early work has found similar effects among children, showing that religious 10-year-olds predict that babies who were adopted at birth would grow up to be the same religion as their birth parents rather than their adoptive parents (Chalik, Rhodes, \& Leslie, 2013). One possibility is that essentialism of religious categories encourages essentialist inferences about the associated religious beliefs. Thus, the current work examined the question of whether children and adults consider the beliefs that partially correspond to religious categories to be rooted in biology and stable over time.

In Study 1, we compared religious beliefs (e.g., "God can do miracles”) with opinions (e.g., "Green is the prettiest color"), ${ }^{1}$ building on prior work revealing that elementary school aged children distinguish between these categories of belief. Children are more likely to report

\footnotetext{
${ }^{1}$ We treat all categories tested in the present work-religious beliefs, factual beliefs, and opinions - as beliefs, i.e., mental representations of particular propositions as being true (Schwitzgebel, 2011). In order to remain consistent with commonly used terminology, however, we refer to "opinions" rather than "opinion-based beliefs."
} 
that only one person can be right in a disagreement concerning religious beliefs than in a disagreement concerning opinions (Heiphetz et al., 2013). Children also judge that religious beliefs reveal more information about the world than do opinions, whereas opinions reveal more information about individuals than do religious beliefs (Heiphetz, Spelke, Harris, et al., 2014). Thus, children may also distinguish between religious beliefs and opinions when answering questions to measure essentialism. Indeed, other work (Harris \& Corriveau, 2014; Harris \& Koenig, 2006; Lane \& Harris, 2014) has proposed that children acquire religious beliefs via testimony. According to this perspective, religious beliefs - but not opinions - are learned from others and do not arise as a result of one's genetic make-up. This perspective might predict that children would view religious beliefs in less essentialist terms than opinions, particularly when answering questions about the extent to which each type of belief is rooted in biology.

Studies 2-3 additionally tested beliefs about facts (e.g., "the Nile is the longest river in the world") — in particular, facts that concern topics about which adults lack knowledge (e.g., adults do not reliably know whether the Nile actually is the longest river; Heiphetz, Spelke, \& Banaji, 2014). We could therefore draw conclusions about the extent to which factual beliefs per se, rather than psychological characteristics such as intelligence (which may be associated with beliefs regarding commonly-known information), elicit components of essentialism. We tested factual beliefs that refer to aspects of the world that are relatively stable (e.g., whether the Nile is the longest river) rather than transient (e.g., whether it is sunny today), a choice that allowed us to test the hypothesis that participants would exhibit some degree of essentialism regarding factual beliefs. Because transient beliefs, by their nature, change with changing conditions, failing to reveal essentialist judgments about these beliefs would not be especially informative and would not allow us to determine whether essentialism regarding factual beliefs is ever 
possible. In contrast, relatively unchanging factual beliefs may evoke essentialist explanations to account for their stability. See Table 1 for a summary of these predictions.

\begin{tabular}{lll}
\hline & Relative Degree of & Relative Degree of \\
& Essentialism: Biological & Essentialism: Stability \\
& Component & Component \\
\hline Religious Beliefs & Medium & Low/Medium \\
Factual Beliefs & Low & Medium \\
Opinions & High & Low \\
\hline
\end{tabular}

Table 1. Summary of predictions regarding essentialism concerning religious beliefs, factual beliefs, and opinions. The designations "high," "medium," and "low" are relative. For example, a "high" designation indicates that the level of essentialism may be higher for one belief than another, not that the level of essentialism would be high by an absolute standard.

\section{Study 1}

The purpose of Study 1 was twofold. First, we sought to determine the extent to which individuals perceive religious beliefs and opinions in essentialist terms, reporting that these beliefs have a biological basis and/or remain stable across time. Second, we sought to investigate the extent to which these judgments vary across development.

\section{Method}

Participants. The sample included 58 children between 8 and 10 years old $\left(M_{\text {age }}=9.02\right.$ years, $S D_{\text {age }}=.74$ years, $41 \%$ female $)$ and 61 adults between 19 and 68 years old $\left(M_{\text {age }}=35.59\right.$ years, $S D_{\text {age }}=11.42$ years, $54 \%$ female). Children were recruited from a local museum and received a sticker. Adults were recruited online using Amazon Mechanical Turk and received 
\$1.00. Data from four additional adults were discarded because they failed to correctly answer an attention check question. The large age range among adults allowed us to test for developmental differences within the adult sample, although no such differences emerged; see Supplementary Materials.

During the session, children's parents completed a demographic questionnaire. Adults completed this questionnaire at the end of the study. Parents identified their children as White or European-American (53\%), Black or African-American (5\%), Asian or Asian-American (10\%), Multiracial (14\%), and "other" (5\%); the remaining parents did not identify their child's race. Additionally, $14 \%$ of children were identified as Hispanic or Latino/a. Parents also identified their children as Protestant (16\%), Catholic (31\%), other Christian denomination (14\%), Jewish (2\%), Muslim (2\%), atheist, agnostic, or none (19\%; these options were grouped together on the questionnaire), and "other" (12\%); the remaining parents did not identify their child's religion. Adults self-identified as White or European-American (75\%), Black or African-American (12\%), Asian or Asian-American (5\%), Multiracial (5\%), and "other" (3\%). Additionally, 12\% of adults self-identified as Hispanic or Latino/a. Adults also self-identified as Protestant (21\%), Catholic (12\%), other Christian denomination (7\%), Jewish (5\%), atheist, agnostic, or none (49\%), and “other" (7\%).

Procedure. Here and in subsequent studies, adult participants provided informed consent prior to beginning the study. Parents of child participants provided informed consent, and children provided verbal assent.

During each of eight trials, the experimenter showed children a photograph of a character on a computer screen and described the character's belief. Photographs were taken from publically accessible websites and showed White children of the same gender as participants. 
Four beliefs were religious (e.g., "This person thinks that God knows everyone's thoughts"), and four were opinions (e.g., "This person thinks that tag is the most fun game to play"; see Appendix). After each belief, the experimenter asked five questions. To probe the biological component of essentialism, we asked the following three questions:

- "In the future, will scientists be able to figure out who thinks $\mathrm{X}$ by looking at their blood under an x-ray or microscope?"

- "Why does this person think X? Is it because he/she was taught to think that?" (reversescored)

- "Look, here is a different person. He/she does not think X. Do you think that this [new] person's brain is different from this [original] person's brain?"

To probe the stability component of essentialism, we asked the following two questions:

- "Do you think that this person can change whether or not he/she thinks X, if he/she wants to?" (reverse-scored).

- "Do you think this person always thought X?"

Essentialism questions were taken from Gelman et al. (2007) and, as in this prior work, children answered by saying "yes," "maybe," or "no." Following the analytic procedure outlined by Gelman et al. (2007), we coded "yes" responses as 1, "no" responses as 0 , and "maybe" responses as .5. We then scored the biological component of essentialism by averaging responses to the first three questions above (concerning whether evidence of the belief could be found in someone's blood, why someone holds the belief they do, and whether two people who believe different things have different brains) across the four religion items (e.g., the item asking about whether God knows everyone's thoughts, the item asking about miracles, etc.) and, separately, the four opinion items. We also scored the stability component of essentialism by averaging 
responses to the last two questions above (concerning whether the belief could change and whether the person always held the belief) across the four religion items and, separately, the four opinion items. Each component was scored such that higher values corresponded to more essentialism.

Based on prior work showing that conceptions of biology and stability form two distinct components of essentialism (Bastian \& Haslam, 2006; Gelman et al., 2007), we divided the questions into those measuring a perceived biological basis and those measuring perceived stability. The decision about which item belonged to which component was also based on previous research using these items (Gelman et al., 2007). For example, in these prior studies, third graders who were told that a person had always had a particular characteristic reported that that characteristic could not change. To gain additional certainty in the reliability of each component among our sample, we calculated alphas for each component. These analyses demonstrated acceptable-to-good reliability (alphas $=.86$ for biology and .79 for stability).

The following were counterbalanced across participants: 1) Order of beliefs; 2) Order of questions after each belief (although this order stayed consistent across beliefs for a given child to avoid confusion); 3) The pairings of particular photographs with particular beliefs. Adults answered the same questions online; however, they did not view photographs. The purpose of the photographs was to draw children's attention to the study, and adults did not require photographs to focus on the task.

\section{Results}

We analyzed responses using a 2 (Belief Type: religious vs. opinion) x 2 (Essentialism Component: biology vs. stability) x 2 (Participant Age: child vs. adult) x 2 (Participant Religion: religious vs. nonreligious) mixed-design ANOVA with repeated measures on the first two 
factors. (For differences among items with each Belief Type for Studies 1-3, see Supplementary

Materials.) This analysis revealed main effects of Belief Type $\left(F(1,112)=19.93, p<.001, \eta_{\mathrm{p}}{ }^{2}=\right.$ $.15)$, Essentialism Component $\left(F(1,112)=28.94, p<.001, \eta_{\mathrm{p}}{ }^{2}=.21\right)$, and Participant Age $(F$ $\left.(1,112)=7.95, p=.006, \eta_{\mathrm{p}}^{2}=.07\right)$. We also found a Belief Type $\mathrm{x}$ Essentialism Component interaction $\left(F(1,112)=61.53, p<.001, \eta_{\mathrm{p}}{ }^{2}=.36\right)$ and an Essentialism Component $\mathrm{x}$ Participant Age interaction $\left(F(1,112)=5.38, p=.022, \eta_{\mathrm{p}}^{2}=.05\right)$. These effects were qualified by a Belief Type $\mathrm{x}$ Essentialism Component $\mathrm{x}$ Participant Age interaction $\left(F(1,112)=5.44, p=.021, \eta_{\mathrm{p}}{ }^{2}=\right.$ $.05)$. No other main effects or interactions reached significance $(p \mathrm{~s} \geq .053){ }^{2}$

To further investigate this three-way interaction (Figure 1), we examined whether participants distinguished between religious beliefs and opinions when answering questions about (a) the extent to which each belief type was rooted in biology and (b) the extent to which each belief type was stable across time. We conducted these analyses separately for children and adults, for a total of four analyses. Therefore, uncorrected $p$ values (reported below) needed to be .013 or lower to pass the Bonferroni-corrected significance threshold.

Children and adults were more likely to report that opinions (versus religious beliefs) were rooted in biology (children: $M_{\text {opinion }}=.59, S D_{\text {opinion }}=.17, M_{\text {religion }}=.42, S D_{\text {religion }}=.20, F(1$, $56)=68.84, p<.001, \eta_{\mathrm{p}}^{2}=.55$; adults: $M_{\text {opinion }}=.44, S D_{\text {opinion }}=.17, M_{\text {religion }}=.29, S D_{\text {religion }}=$ $\left..18, F(1,60)=56.46, p<.001, \eta_{\mathrm{p}}^{2}=.49\right)$. Furthermore, children reported that opinions were less

\footnotetext{
${ }^{2}$ All effect sizes in the current manuscript correspond to partial eta squared. To our knowledge, there is little consensus on what represents a "small," "medium," or "large" value for this statistic. However, Cohen (1988) recommended that for eta squared, .02 corresponds to a "small" effect size, . 13 corresponds to a "medium" effect size, and .26 corresponds to a "large" effect size, and some researchers follow these guidelines when interpreting partial eta squared values. Furthermore, because all analyses reported here use the same measure of effect size, effects can be compared relative to each other. However, the absolute magnitude may be of greater interest than the relative magnitude. For example, researchers may wish to attend more to whether two effects are both small rather than focusing on whether one small effect is slightly larger than another small effect.
} 
stable than religious beliefs $\left(M_{\text {opinion }}=.24, S D_{\text {opinion }}=.17, M_{\text {religion }}=.32, S D_{\text {religion }}=.22, F(1,56)\right.$ $=12.57, p=.001, \eta_{\mathrm{p}}^{2}=.18$ ), although this difference was smaller in magnitude than the difference in children's reports of how much each type of belief was rooted in biology, and adults did not draw this distinction $\left(M_{\text {opinion }}=.29, S D_{\text {opinion }}=.17, M_{\text {religion }}=.30, S D_{\text {religion }}=.23, F\right.$ $\left.(1,60)=.03, p=.862, \eta_{\mathrm{p}}^{2}<.01\right)$. To measure perceptions of the biological basis and stability of beliefs against an absolute standard in addition to the relative comparisons presented here, we also compared (in this and subsequent studies) children's and adults' judgments of each belief type to the scale's midpoint (.50); see Supplementary Materials.

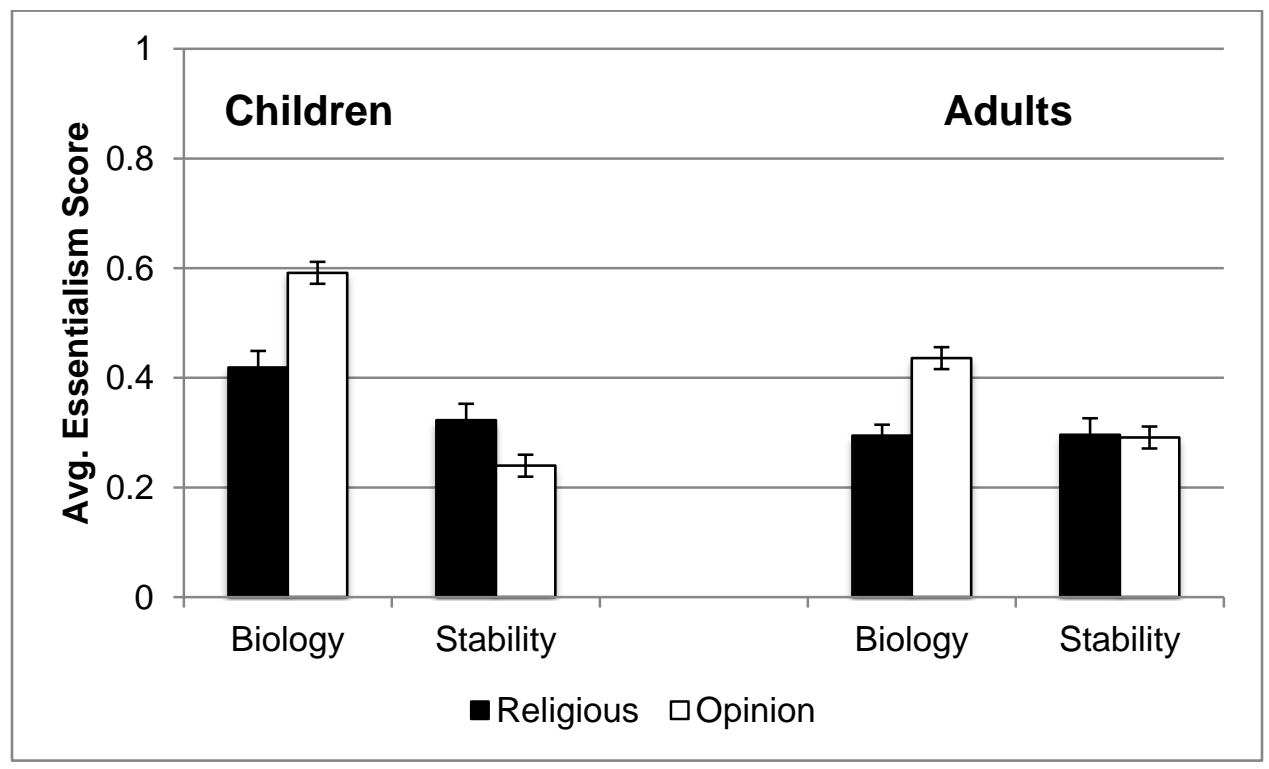

Figure 1. Average scores for the biology and stability components of essentialism, Study 1. Error bars represent the standard error of the mean.

Although the two components of essentialism showed different patterns at the group level, it is possible that some individuals are generally high in essentialism while other individuals are generally low in essentialism. That is, responses to questions about the biological component of essentialism may be associated with responses to questions about the stability component of essentialism. To test this possibility, we correlated responses to questions about 
the biological component and responses to questions about the stability component for religious beliefs and, separately, for opinions. We conducted these analyses separately among children and adults, for a total of four correlations. None of these analyses reached significance $(|r| \mathrm{s} \leq .04$, uncorrected $p s \geq .77$ ), providing more evidence in support of the assertion that the two components of essentialism are separable. These analyses also failed to reveal a reliable association between the two components of essentialism in Studies 2 and 3; see Supplementary Materials.

\section{Discussion}

Study 1 investigated the extent to which children and adults judge religious beliefs and opinions to be (a) rooted in biology and (b) stable over time. In line with prior work (Gelman et al., 2007; Bastian \& Haslam, 2006), participants in the current study responded differently to questions tapping these two components of essentialism. Both children and adults reported that opinions were more rooted in biology than religious beliefs. This finding may reflect individuals' different subjective experiences of acquiring each belief type. They may recollect learning religious beliefs from others while feeling that their opinions arose spontaneously from an internal source (see General Discussion).

Higher rates of essentialism for opinions than religious beliefs were limited to the biological component. By contrast, children perceived religious beliefs to be more stable than opinions, although the magnitude of this effect was relatively small compared with children's perception that opinions were more rooted in biology than religious beliefs. Furthermore, adults reported that religious beliefs and opinions were equally changeable.

\section{Study 2}


The main goals of Study 2 were twofold. First, we sought to replicate the results from Study 1. Second, we examined the extent to which individuals perceive factual beliefs, as well as religious beliefs and opinions, as rooted in biology and stable across time. Children distinguish religious beliefs from both of these other categories when judging how many people can be right in a disagreement (Heiphetz et al., 2013) and when indicating how much each type of belief reveals about the world versus the person holding the belief (Heiphetz, Spelke, Harris, et al., 2014). In particular, along these dimensions, religious beliefs occupy an intermediate position (e.g., children are more likely to say that only one person can be right when judging religious disagreement versus disagreement over opinions, but they are less likely to say that only one person can be right when judging religious disagreement versus factual disagreement; Heiphetz et al., 2013). We sought to discover whether religious beliefs occupy a similar intermediate position in judgments regarding the biological basis and stability of these beliefs.

\section{Method}

Participants. The sample included 50 children between 8 and 10 years old $(M=8.96$ years, $S D=.64$ years, $50 \%$ female, $80 \%$ White $)$ and 59 adults between 19 and 63 years old $(M=$ 34.24 years, $S D=11.20$ years, $58 \%$ female, $80 \%$ White) who had not participated in Study 1 . Children were recruited in a local school district; they completed the study in a quiet area and received a sticker. Their demographic information was recorded from questionnaires completed by their parents and returned to the school along with consent forms. Adults were recruited online using Amazon Mechanical Turk and received \$1.00. They completed the demographic information immediately after answering the experimental questions. Data from six additional adults were discarded because they failed to correctly answer an attention check question $(N=3)$ or because they had participated in Study $1(N=3)$. 
Procedure. The experimenter introduced the study by saying, "I'm going to ask you some questions about you. I'm also going to tell you about people who live here on Earth. All the people I'm going to tell you about live here.” An explicit reference to Earth was included to provide a match for Study 3, which presented information about a different planet (see below). As in Study 1, participants were instructed that they could answer questions by saying "yes," "maybe," or "no."

Participants were exposed to two religious beliefs and two opinions from Study 1. They also learned about two factual beliefs (e.g., "This person thinks that the Nile is the longest river in the world") that were based on specialized expertise. On each trial, participants answered the same questions as in Study 1, with three exceptions. First, the first question on each trial asked participants to indicate their own belief ("Some people think X, and some people think Y. Which do you think?"). Participants then learned about a particular character's belief and answered the questions from Study 1. The purpose of the initial question was to allow us to determine the extent to which levels of essentialism varied according to whether or not participants reported the same belief as the character. Second, after asking participants to indicate whether the character could think something different when he/she grew up, the experimenter asked whether the character would maybe, probably, or definitely think the same thing (if participants said "no"), or whether the character would maybe, probably, or definitely think something different (if participants said "yes"), or whether the character would probably think something different or probably think the same thing (if participants said "maybe"). The purpose of this follow-up question was to measure the degree to which participants were certain that the belief would change or stay the same; see Supplementary Materials for analyses of this item. Third, to allow children enough time to answer these additional questions, we tested two items per category 
(rather than four items, as in Study 1). Stimuli were counterbalanced as in Study 1. Adults completed this procedure online and did not view pictures of characters.

\section{Results}

Data were scored as in Study 1 and analyzed using a 3 (Belief Type: religious vs. opinion vs. factual) x 2 (Essentialism Component: biology vs. stability) x 2 (Participant Age: child vs. adult) mixed-design ANOVA with repeated measures on the first two factors. We did not include participant religion as a factor because this variable did not exert a significant main effect or interact with any other variables in Study 1 (for other studies showing similar patterns across religious groups, see Heiphetz et al., 2013; Heiphetz, Spelke, \& Banaji, 2014) and because we did not have a large enough sample size of non-theists to compare participants from different backgrounds. This analysis revealed three main effects: Belief Type $\left(F(1.85,197.86)^{3}=4.08, p\right.$ $\left.=.022, \eta_{\mathrm{p}}{ }^{2}=.04\right)$, Essentialism Component $\left(F(1,107)=52.45, p<.001, \eta_{\mathrm{p}}{ }^{2}=.33\right)$, and Participant Age $\left(F(1,107)=11.20, p=.001, \eta_{\mathrm{p}}{ }^{2}=.10\right)$. We also found a Belief Type $\mathrm{x}$ Essentialism Component interaction $\left(F(1.87,200.37)=27.52, p<.001, \eta_{\mathrm{p}}{ }^{2}=.21\right)$ and an Essentialism Component x Participant Age interaction $\left(F(1,107)=178.24, p<.001, \eta_{\mathrm{p}}{ }^{2}=.63\right)$, although the Belief Type x Participant Age interaction failed to reach significance $(F(1.85$, $\left.197.86)=2.83, p=.066, \eta_{\mathrm{p}}^{2}=.03\right)$. As in Study 1 , the significant main effects and interactions were qualified by a Belief Type x Essentialism Component x Participant Age interaction ( $F$ $(1.87,200.37)=5.09, p=.008, \eta_{\mathrm{p}}^{2}=.05 ;$ Figure 2$)$.

\footnotetext{
${ }^{3}$ All non-integer degrees of freedom are the result of applying a Greenhouse-Geisser adjustment to correct for a violation of the assumption of sphericity.
} 


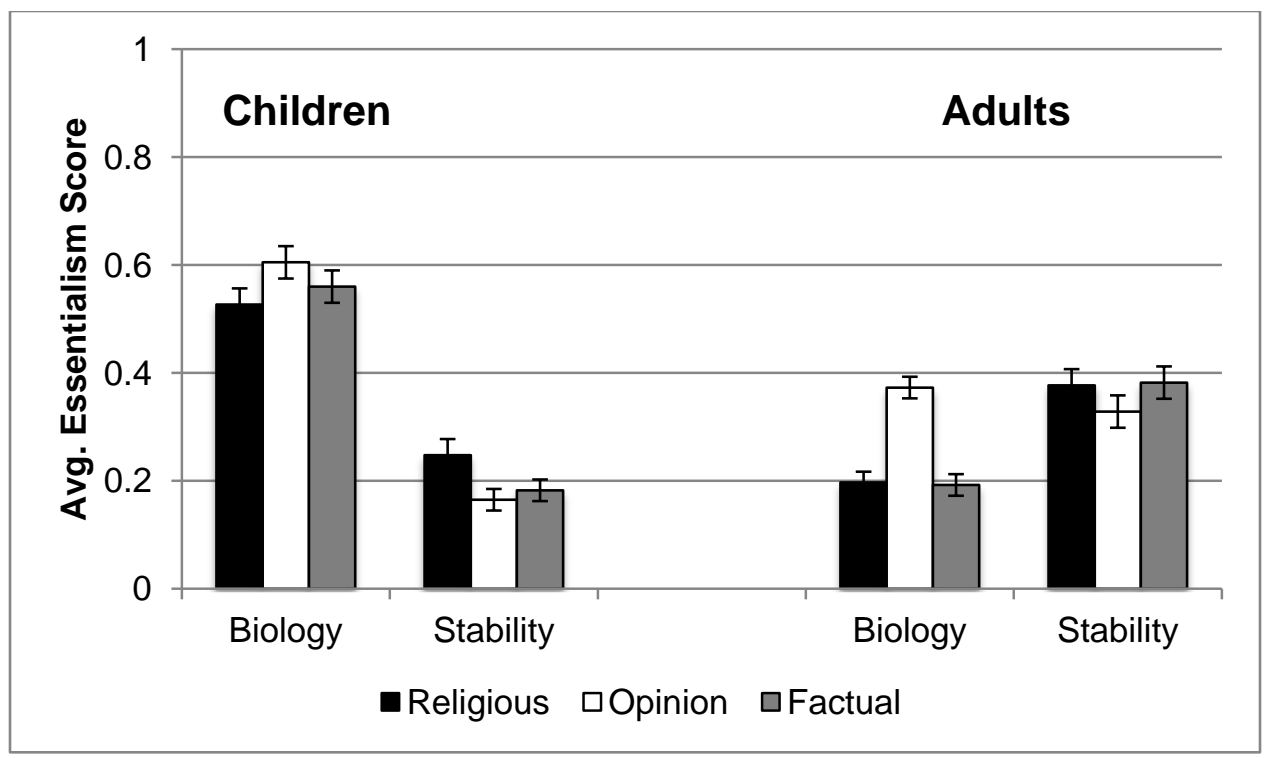

Figure 2. Average scores for the biology and stability components of essentialism, Study 2. Error bars represent the standard error of the mean.

As in Study 1, we examined the extent to which each belief type, as compared with each other belief type, was perceived to be (a) rooted in biology and (b) stable across time. We conducted these analyses separately for children and adults, for a total of 12 comparisons. Therefore, uncorrected $p$ values (reported below) needed to be .004 or lower to pass the Bonferroni-corrected significance threshold.

Follow-up tests showed that, as in Study 1, children reported that opinions $(M=.61, S D$ $=.18)$ were more rooted in biology than were religious beliefs $(M=.53, S D=.20)$. However, due to the greater number of comparisons in Study 2, this difference did not pass the more stringent Bonferroni-corrected significance threshold $\left(F(1,49)=7.88, p=.007, \eta_{\mathrm{p}}{ }^{2}=.14\right)$. Also as in Study 1, adults exhibited the same pattern, and the difference among adults was larger than the difference among children $\left(M_{\text {opinion }}=.38, S D_{\text {opinion }}=.15, M_{\text {religion }}=.20, S D_{\text {religion }}=.18, F(1\right.$, $\left.58)=70.70, p<.001, \eta_{\mathrm{p}}{ }^{2}=.55\right)$. Furthermore, adults reported that opinions were more rooted in biology than factual beliefs $\left(M_{\text {fact }}=.19, S D_{\text {fact }}=.17, F(1,58)=99.10, p<.001, \eta_{\mathrm{p}}{ }^{2}=.63\right)$. No 
other differences in perceptions of biology passed the Bonferroni-corrected significance threshold ( $p s \geq .041)$. As in Study 1, children reported that opinions were less stable than religious beliefs $\left(F(1,49)=9.60, p=.003, \eta_{\mathrm{p}}{ }^{2}=.16\right)$. No other differences in perceptions of stability passed the Bonferroni-corrected significance threshold ( $p \mathrm{~s} \geq .031)$.

In addition to these analyses, we conducted several tests to examine whether participants' responses depended on whether they agreed or disagreed with the characters' beliefs. No relation emerged between these variables; see Supplementary Materials for these analyses for Studies 2 and 3.

\section{Discussion}

The first goal of Study 2 was to replicate the results from Study 1. Indeed, we found largely similar patterns of results across the two studies.

The second goal of Study 2 was to investigate children's and adults' judgments concerning factual beliefs. One difference emerged between factual beliefs and the other belief types we tested: adults, but not children, reported that opinions were more rooted in biology than factual beliefs. This result occurred because adults reported that factual beliefs were not strongly rooted in biology, whereas children did not draw this conclusion (see Supplementary Materials for analyses comparing essentialism regarding each belief type to an absolute standard). Past work has shown that essentialist judgments of social groups and psychological characteristics decrease across age (Gelman et al., 2007; Heyman \& Gelman, 2000; Taylor, 1996). The current results suggest that this pattern extends to beliefs and therefore lends support to the idea that essentialism may serve as a default way of perceiving the world that adults override after learning about how the environment can influence characteristics (Eidson \& Coley, 2014; Gelman et al., 2007). 
Interestingly, the current findings differ from prior work comparing religious beliefs, factual beliefs, and opinions. In this prior work, children and adults distinguished among all three belief types when judging disagreements (Heiphetz et al., 2013; Heiphetz, Spelke, Harris, et al., 2014). The current findings indicate that such distinctions are limited to some domains (e.g., epistemology) and that individuals do not distinguish among these belief types along all dimensions.

\section{Study 3}

The main goal of Study 3 was to determine the extent to which findings from Study 2 were informed by participants' prior experience with the beliefs we tested. Because all items in Study 2 were beliefs that individuals could actually hold, participants may have arrived with prior experience regarding the distribution of these beliefs. For example, they may have learned that the specific belief "God can do miracles" is not randomly distributed throughout the population but is, in fact, associated with membership in an essentialized religious group (Toosi \& Ambady, 2011). Furthermore, participants' observations of the frequency with which individuals change their minds about such beliefs may have influenced conclusions about belief stability. Thus, it is not clear whether responses in Study 2 were driven by the specific, familiar beliefs we tested, or, of greater relevance to the current work, whether these responses indicated a way of thinking about belief types - e.g., religious beliefs, including those with which participants have no prior experience. To distinguish between these possibilities, Study 3 tested unfamiliar beliefs.

\section{Method}

Participants. The sample included 53 children between 8 and 10 years old $(M=8.77$ years, $S D=.67$ years, $49 \%$ female, $74 \%$ White $)$ and 58 adults between 19 and 65 years $(M=$ 
34.19 years, $S D=10.27$ years, $36 \%$ female, $83 \%$ White) who had not participated in Studies 1 or

2. Recruitment procedures were identical to Study 2. Data from seven additional adults were discarded because they failed to correctly answer an attention check question.

Procedure. The experimenter introduced the study to children by saying, "I'm going to ask you some questions about you. I'm also going to tell you about people who live on a planet that's really far away from here called Tamsena. All the people I'm going to tell you about live there." Participants received the same instructions concerning using the scale as in Study 2.

As in Study 2, participants were exposed to two religious beliefs, two opinions, and two factual beliefs. Beliefs from Study 2 were adapted to fit the context of another planet. For example, the experimenter said, "Some people think that Ashamari, the goddess of Tamsena, can hear people when they pray out loud, and some people think that only other people can hear everyone when they pray out loud. Which do you think?" The experimenter then showed children a picture of another child and said, "Look, this person thinks that Ashamari can hear everyone when they pray out loud." Finally, the experimenter asked all five questions from Study 1 before moving on to the next item (see Appendix for all items). Adults completed this procedure online. As in Studies 1 and 2, adults did not view pictures of characters.

\section{Results}

Data were scored as in Study 2 and analyzed using a 3 (Belief Type: religious vs. opinion vs. factual) x 2 (Essentialism Component: biology vs. stability) x 2 (Participant Age: child vs. adult) mixed-design ANOVA with repeated measures on the first two factors. The results provided a conceptual replication of Study 2. That is, this analysis revealed three main effects: Belief Type $\left(F(1.79,194.86)=5.16, p=.009, \eta_{\mathrm{p}}{ }^{2}=.05\right)$, Essentialism Component $(F(1,109)=$ 29.83, $\left.p<.001, \eta_{\mathrm{p}}{ }^{2}=.22\right)$, and Participant Age $\left(F(1,109)=23.67, p<.001, \eta_{\mathrm{p}}{ }^{2}=.18\right)$. We also 
found a Belief Type $\mathrm{x}$ Essentialism Component interaction $\left(F(1.84,201)=32.17, p<.001, \eta_{\mathrm{p}}{ }^{2}\right.$ $=.23)$ and an Essentialism Component x Participant Age interaction $(F(1,109)=95.50, p<$ $\left..001, \eta_{\mathrm{p}}{ }^{2}=.47\right)$, although the Belief Type $\mathrm{x}$ Participant Age interaction failed to reach significance $\left(F(1.79,194.86)=2.35, p=.104, \eta_{\mathrm{p}}{ }^{2}=.02\right)$. These significant main effects and interactions were qualified by a Belief Type x Essentialism Component x Participant Age interaction $\left(F(1.84,201)=9.00, p<.001, \eta_{\mathrm{p}}^{2}=.08\right)$.

To investigate this three-way interaction (Figure 3), we conducted 12 follow-up tests examining differences among belief types for children and, separately, adults. Thus, uncorrected $p$ values (reported below) needed to be .004 or lower to pass the Bonferroni-corrected significance threshold. As in Study 1, both children and adults reported that opinions were more rooted in biology than religious beliefs, and the magnitude of this effect was larger among adults than among children (children: $M_{\text {opinion }}=.62, S D_{\text {opinion }}=.16, M_{\text {religion }}=.55, S D_{\text {religion }}=.21, F(1$, $52)=9.06, p=.004, \eta_{\mathrm{p}}{ }^{2}=.15$; adults: $M_{\text {opinion }}=.37, S D_{\text {opinion }}=.15, M_{\text {religion }}=.24, S D_{\text {religion }}=.19$, $\left.F(1,57)=45.31, p<.001, \eta_{\mathrm{p}}^{2}=.44\right)$. Furthermore, adults reported that factual beliefs were less rooted in biology than either religious beliefs $\left(M_{\mathrm{fact}}=.19, S D_{\text {fact }}=.16, F(1,57)=9.56, p=.003\right.$, $\left.\eta_{\mathrm{p}}{ }^{2}=.14\right)$ or opinions $\left(F(1,57)=116.74, p<.001, \eta_{\mathrm{p}}{ }^{2}=.67\right)$, although children did not draw these distinctions ( $p s \geq .083$ ). Finally, adults also reported that religious beliefs were more stable than opinions $\left(M_{\text {religion }}=.41, S D_{\text {religion }}=.26, M_{\text {opinion }}=.31, S D_{\text {opinion }}=.20, F(1,57)=10.28, p=\right.$ $\left..002, \eta_{\mathrm{p}}{ }^{2}=.15\right)$. No other pairwise comparisons in perceptions of stability passed the Bonferronicorrected significance threshold $(p s \geq .023)$. 


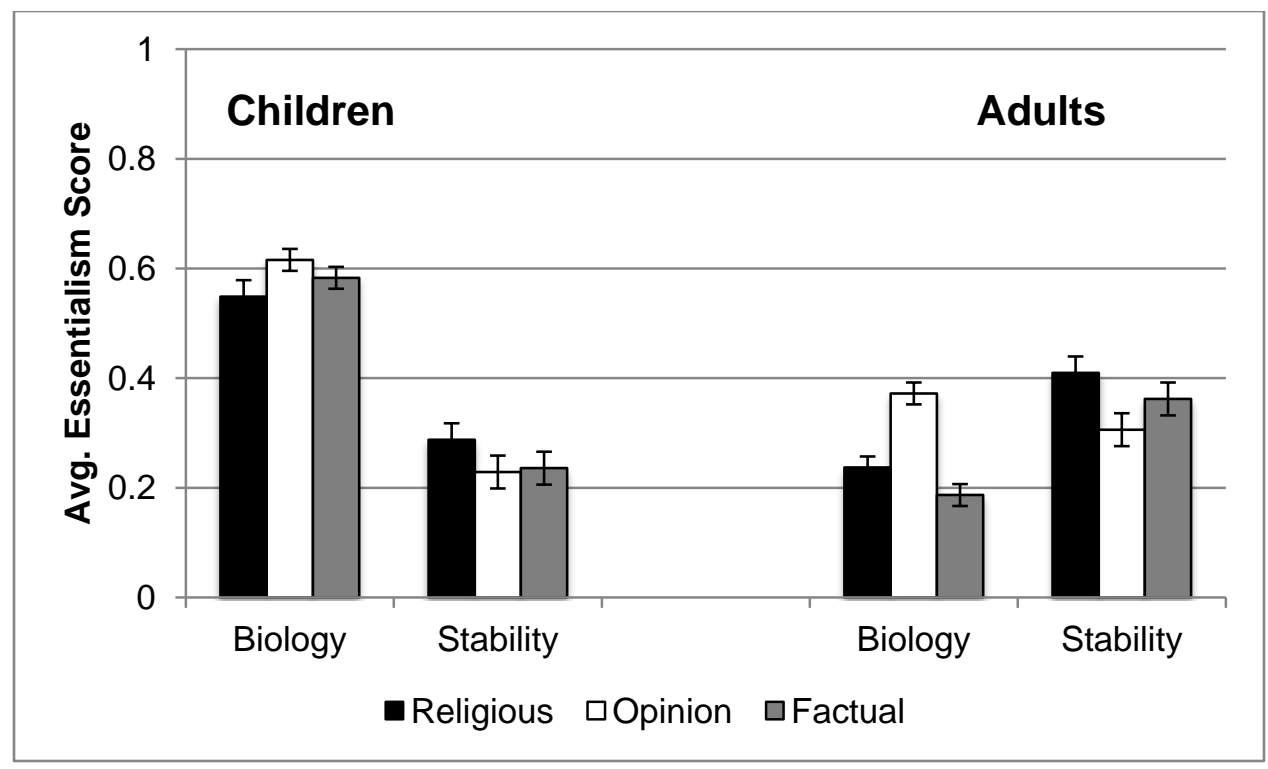

Figure 3. Average scores for the biology and stability components of essentialism, Study 3. Error bars represent the standard error of the mean.

\section{Discussion}

The goal of Study 3 was to clarify the extent to which the results from Study 2 were due to judgments concerning specific familiar beliefs versus judgments concerning belief categories more broadly. To achieve this goal, Study 3 tested unfamiliar beliefs. The results of Studies 2 and 3 were broadly consistent. In both studies, children and adults reported especially essentialist views of opinions when answering questions about the biological basis of each belief type, whereas consistent differences among belief types did not emerge when participants answered questions about each belief's stability. Furthermore, in neither study did responses to questions about the biological component of essentialism predict responses to questions about the stability component. These patterns do not appear to reflect familiarity with specific belief exemplars but may, instead, indicate a more generalized way of thinking about different belief types.

We did find one exception to the overall pattern of similarity between Studies 2 and 3: although factual beliefs did not differ from either religious beliefs or opinions on the stability 
component of essentialism in either study, only children in Study 2, and only adults in Study 3, reported that religious beliefs were more stable than opinions. Future work may test whether this reflects a replicable exception to the overall similarity between individuals' judgments of familiar versus novel beliefs.

\section{General Discussion}

The goal of the present research was to investigate the extent to which children and adults perceive beliefs in an essentialist way — that is, as having a biological basis and/or as remaining stable over time. Taken together, Studies 1-3 reveal three main findings. We briefly summarize these findings below before turning to implications.

First, both children and adults drew some distinctions among belief types when answering questions about the biological component of essentialism. Participants in both age groups typically reported that opinions were more rooted in biology than were religious beliefs. Furthermore, adults in Studies 2 and 3 perceived opinions to be more rooted in biology than were factual beliefs. Children did not draw this distinction between opinions and factual beliefs. Instead, they reported that factual beliefs had a relatively strong biological basis (especially in Study 3), whereas adults reported that factual beliefs had a relatively low biological basis (see Supplementary Materials).

Second, neither children nor adults showed a strong propensity to distinguish among belief types when judging the stability component of essentialism. For example, participants in both age groups judged that factual beliefs were just as changeable as religious beliefs and opinions. Although religious beliefs were sometimes judged to be more stable than opinions, this finding was not consistent across age groups and should be replicated in future research before being strongly interpreted. 
Third, we observed many similarities between Study 2, which tested familiar beliefs, and Study 3, which tested novel beliefs. Taken together, these two studies indicate that the patterns of results observed in Study 2 did not depend on prior knowledge of specific beliefs. Rather, the observed patterns may reflect deeper judgments about the nature of religious beliefs, factual beliefs, and opinions (i.e., judgments about the entire category of religious beliefs rather than about specific, familiar exemplars of this category).

The current findings have several implications for the study of essentialism. First, they demonstrate the pervasiveness of this perspective. Intuitively, it appears implausible that any beliefs would elicit essentialism to any extent. After all, people often learn their beliefs from others, and these beliefs may change over time. Nevertheless, many beliefs are perceived to be unchosen (e.g., people cannot simply will themselves to believe that broccoli is delicious or that playing tag is fun), and prior work has found more evidence of genetic attributions regarding unchosen rather than chosen characteristics (Jayaratne et al., 2009). Although the current work did not uncover high levels of essentialism for religious beliefs or factual beliefs, these belief types did elicit some degree of essentialism; indeed, children (as compared with adults) were especially likely to report that these beliefs had some biological basis. Additionally, participants at both ages perceived a strong biological basis for opinions. Given the a priori reasons to expect that beliefs might not elicit essentialist judgments, these findings represent an important advance in revealing the pervasive nature of essentialism.

Second, the current results suggest that the biological component and the stability component of essentialism may not be strongly linked, at least with the sorts of stimuli examined in this set of studies. Correlations between these components failed to reach significance, and while opinions were judged to be more deeply rooted in biology than religious beliefs, they were 
also sometimes judged to be less stable across time. In our view, biology and stability are not two distinct forms of essentialism but rather two separable components of essentialism, broadly construed. If a characteristic is perceived as arising from a biological source, that characteristic would be high in the biological component of essentialism, and therefore would be essentialized in some way regardless of how stable it is perceived to be. An analogy may help illustrate this point: The propensity to exhibit colic in infancy could have a biological basis, but this does not mean that the colicky baby would continue to exhibit colic as an older child or adult. Similarly, although individuals may perceive that their opinions arise from internal sources, it is also easy to see how opinions can change over time; a child who enjoys playing tag is unlikely to grow into an adult who has this preference. Nonetheless, although the dimensions can be separated, they may often be confounded for natural kinds (e.g., a giraffe's long neck is both biologically determined and stable), for artifacts (e.g., the shape of a paper cup is neither biologically determined nor stable), and even for certain psychological characteristics (e.g., intelligence is often viewed as both biologically determined and stable; Gelman et al., 2007).

It may be that different factors underlie the two components. In particular, one common cultural narrative in the United States emphasizes that people can become anything they want to be and, thus, that it is possible for characteristics to change across time. This narrative is reflected in popular children's media such as You can be anything! (the title of at least two books, one by Charles Schulz and the other by Gary Craig, as well as a video featuring Barney and Friends). This worldview may have encouraged participants to report that all beliefs could change, leading to relatively low rates of essentialism in response to questions about stability across all of the belief types tested here. In contrast, American culture does not propagate an overarching narrative regarding the extent to which characteristics in general are based in 
biology; rather, some characteristics are portrayed in more biological terms than others.

Reflecting this pattern, participants in the current work perceived some beliefs (e.g., opinions) to be more rooted in biology than other beliefs (e.g., religious beliefs). This difference may occur as a result of participants' experiences acquiring each type of belief. Religious beliefs are frequently acquired from others via testimony (Harris \& Corriveau, 2014; Harris \& Koenig, 2006; Lane \& Harris, 2014), whereas opinions may be perceived as arising from an internal source.

The current work uncovered developmental differences in essentialism while also revealing similarities in children's and adults' perceptions of religious beliefs, factual beliefs, and opinions. Consistent with prior work (Gelman et al., 2007; Heyman \& Gelman, 2000; Taylor, 1996), the current research showed that children perceived a greater biological basis underlying beliefs than did adults. For example, whereas children in Study 3 reported a relatively strong biological basis of factual beliefs, adults reported relatively low levels. Prior work (Eidson \& Coley, 2014; Gelman et al., 2007) has suggested that essentialism may be a cognitive default that adults effortfully override with information about environmental influences on human characteristics. The current work supports this position and extends knowledge of the development of essentialism (particularly its biological component) to the previously unstudied domain of beliefs.

Despite this developmental difference, the relation among belief types tended to remain consistent across age groups. For example, both children and adults reported that opinions were more deeply rooted in biology than religious beliefs and that factual beliefs were as changeable as these other two belief types. This finding suggests that development and social experience may play a larger role in individuals' propensity to view beliefs in general as rooted in biology 
and stable across time. Development and social experience appear to play a smaller role in perceptions of different beliefs in relation to each other.

Future work could determine whether the differences between different components of essentialism observed here would emerge in Eastern cultures. As discussed above, American children may be exposed to narratives that emphasize the changeability of characteristics over time. Eastern cultures may place less emphasis on free choice (Savani, Markus, Naidu, Kumar, $\&$ Berlia, 2010); thus, cultural differences may emerge in the perception that people can choose to change their beliefs over time.

The current results may appear puzzling when viewed alongside prior work on religious essentialism, which suggests that some religious group memberships (e.g., Judaism) are viewed to some extent as rooted in biology and stable across time (Chalik et al., 2013; Segev et al., 2012; Toosi \& Ambady, 2011). Taken together, the prior studies and the current work appear to indicate that religious groups elicit more essentialism than the beliefs associated with those groups. However, religious groups that tend to elicit the most essentialism, such as Judaism, deemphasize the importance of beliefs in relation to other determinants of religious identity, such as cultural heritage (Cohen, 2015). Thus, the propensity to view membership in these groups as biological and stable may derive from viewing cultural origins, rather than beliefs, as biological and unchanging. This possibility remains open for future testing.

Future work can also directly examine potential differences between beliefs and other psychological characteristics. The current work suggests potential differences between beliefs and other characteristics that have been commonly studied in the essentialism literature. Like many of the traits studied in this literature, beliefs are internal properties that are not readily apparent from physical appearance. However, there are also a number of differences between 
beliefs and characteristics such as intelligence and shyness, and therefore it may not be appropriate to conceptualize beliefs as belonging to the same category as other psychological characteristics. Of most relevance to the current work, beliefs appear to elicit less essentialism than some other traits. Future work can test this hypothesis directly by examining beliefs as well as more commonly studied traits in the same paradigm.

Finally, future work can ask participants to explain their judgments. Differences in mean ratings, such as those obtained in the current work, provide useful insight into participants' understanding of different types of beliefs. However, participants' explanations could afford greater insight into the cognitive processes underlying these judgments.

\section{Conclusions}

To our knowledge, the current work is among the first to investigate the extent to which children and adults perceive beliefs to be (a) rooted in biology and (b) stable across time. The present findings showed that the biological component of essentialism varied across belief types. Notably, both children and adults viewed opinions as more rooted in biology than religious beliefs. However, participants did not draw strong and consistent distinctions among belief types when judging belief stability. Indeed, participants appeared to perceive the beliefs tested here as changeable. Although children typically exhibited more essentialism than adults, the relation among belief types remained relatively consistent across age groups, suggesting that development and social learning may play a stronger role in determining overall levels of essentialism than relative degrees of essentialism regarding different beliefs. 


\section{References}

Barro, R., Hwang, J., \& McCleary, R. (2010). Religious conversion in 40 countries. Journal for the Scientific Study of Religion, 49, 15-36. doi: 10.1111/j.1468-5906.2009.01490.x

Bastian, B., \& Haslam, N. (2006). Psychological essentialism and stereotype endorsement. Journal of Experimental Social Psychology, 42, 228-235. doi: 10.1016/j.jesp.2005.03.003

Bering, J. M., Blasi, C. H., \& Bjorklund, D. F. (2005). The development of 'afterlife' beliefs in religiously and secularly schooled children. British Journal of Developmental Psychology, 23, 587-607. doi: 10.1348/026151005X36498

Chalik, L., Rhodes, M., \& Leslie, S. J. (2013). Culture and the development of social essentialism: How children reason about religious categories. Poster presented at the biennial meeting of the Cognitive Development Society. Memphis, TN.

Chao, M. M., Hong, Y., \& Chiu, C. (2013). Essentializing race: Its implications on racial categorization. Journal of Personality and Social Psychology, 104, 619-634. doi: $10.1037 / \mathrm{a} 0031332$

Chernyak, N., Kushnir, T., Sullivan, K. M., \& Wang, Q. (2013). A comparison of American and Nepalese children's concepts of freedom of choice and social constraint. Cognitive Science, 37, 1343-1355. doi: 10.1111/cogs.12046

Cimpian, A., \& Salomon, E. (2014). The inherence heuristic: An intuitive means of making sense of the world, and a potential precursor to psychological essentialism. Behavioral and Brain Sciences, 37, 461-527. doi: 10.1017/S0140525X13002197

Cohen, A. B. (2015). Religion's profound influences on psychology: Morality, intergroup relations, self-construal, and enculturation. Current Directions in Psychological Science, 24, 77-82. doi: 10.1177/096372141455326 
Cohen, J. (1988). Statistical power analysis for the behavioral sciences. Hillsdale, NJ: Lawrence Erlbaum.

Dar-Nimrod, I., \& Heine, S. J. (2011). Genetic essentialism: On the deceptive determinism of DNA. Psychological Bulletin, 137, 800-818. doi: 10.1037/a0021860

Dar-Nimrod, I., Heine, S. J., Cheung, B. Y., \& Schaller, M. (2011). Do scientific theories affect men's evaluations of sex crimes? Aggressive Behavior, 37, 440-449. doi: 10.1002/ab.20401

Diesendruck, G., Birnbaum, D., Deeb, I., \& Segall, G. (2013). Learning what is essential: Relative and absolute changes in children's beliefs about the heritability of ethnicity. Journal of Cognition and Development, 14, 546-560. doi:

$10.1080 / 15248372.2012 .691142$

Eidson, R. C., \& Coley, J. D. (2014). Not so fast: Reassessing gender essentialism in young adults. Journal of Cognition and Development, 15, 382-392. doi:

$10.1080 / 15248372.2013 .763810$

Erdley, C. A., \& Dweck, C. S. (1993). Children's implicit personality theories as predictors of their social judgments. Child Development, 64, 863-878. doi: $10.2307 / 1131223$

Gaither, S. E., Schultz, J. R., Pauker, K., Sommers, S. R., Maddox, K. B., \& Ambady, N. (2014). Essentialist thinking predicts decrements in children's memory for racially ambiguous faces. Developmental Psychology, 50, 482-488. doi: $10.1037 / \mathrm{a} 0033493$

Gelman, S. A. (2003). The essential child: Origins of essentialism in everyday thought Oxford University Press, New York, NY. 
Gelman, S. A., Heyman, G. D., \& Legare, C. H. (2007). Developmental changes in the coherence of essentialist beliefs about psychological characteristics. Child Development, 78, 757-774. doi: 10.1111/j.1467-8624.2007.01031.x

Gelman, S. A., \& Wellman, H. M. (1991). Insides and essence: Early understandings of the nonobvious. Cognition, 38, 213-244. doi: 10.1016/0010-0277(91)90007-Q

Gervais, W. M., Shariff, A. F., \& Norenzayan, A. (2011). Do you believe in atheists? Distrust is central to anti-atheist prejudice. Journal of Personality and Social Psychology, 101, 1189-1206. doi: 10.1037/a0025882

Gil-White, F. (2001). Are ethnic groups biological "species" to the human brain? Essentialism in our cognition of some social categories. Current Anthropology, 42, 515-554. doi: $10.1086 / 321802$

Gottfried, G. M., Gelman, S. A., \& Schultz, J. (1999). Children's understanding of the brain: From early essentialism to biological theory. Cognitive Development, 14, 147-174. doi: 10.1016/S0885-2014(99)80022-7

Guerrero, S., Enesco, I., \& Harris, P. L. (2010). Oxygen and the soul: Children's conception of invisible entities. Journal of Cognition and Culture, 10, 123-151. doi: $10.1163 / 156853710 X 497202$

Harris, P. L., \& Corriveau, K. H. (2014). Learning from testimony about religion and science. In E. J. Robinson \& S. Einav (Eds.), Trust and skepticism: Children's selective learning from testimony (pp. 28-41). New York, NY: Psychology Press.

Harris, P. L., \& Koenig, M. A. (2006). Trust in testimony: How children learn about science and religion. Child Development, 77, 505-524. doi: 10.1111/j.1467-8624.2006.00886.x 
Haslam, N., Bastian, B., \& Bissett, M. (2004). Essentialist beliefs about personality and their implications. Personality and Social Psychology Bulletin, 30, 1661-1673. doi: $10.1177 / 0146167204271182$

Haslam, N., \& Levy, S. R. (2006). Essentialist beliefs about homosexuality: Structure and implications for prejudice. Personality and Social Psychology Bulletin, 32, 471-485. doi: $10.1177 / 0146167205276516$

Haslam, N., Rothschild, L., \& Ernst, D. (2000). Essentialist beliefs about social categories. British Journal of Social Psychology, 39, 113-127. doi: 10.1348/014466600164363

Heiphetz, L., Spelke, E. S., \& Banaji, M. R. (2014). The formation of belief-based social preferences. Social Cognition, 32, 22-47. doi: 10.1521/soco.2014.32.1.22

Heiphetz, L., Spelke, E. S., Harris, P. L., \& Banaji, M. R. (2013). The development of reasoning about beliefs: Fact, preference, and ideology. Journal of Experimental Social Psychology, 49, 559-565. doi: 10.1016/j.jesp.2012.09.005

Heiphetz, L., Spelke, E. S., Harris, P. L., \& Banaji, M. R. (2014). What do different beliefs tell us? An examination of factual, opinion-based, and religious beliefs. Cognitive Development, 30, 15-29. doi: 10.1016/j.cogdev.2013.12.002

Heyman, G. D., \& Dweck, C. S. (1998). Children's thinking about traits: Implications for judgments of the self and others. Child Development, 69, 391-403. doi: 10.2307/1132173

Heyman, G. D., \& Gelman, S. A. (2000). Beliefs about the origins of human psychological traits. Developmental Psychology, 36, 663-678. doi: 10.1037/0012-1649.36.5.663

Ho, A. K., Roberts, S. O., \& Gelman, S. A. (2015). Essentialism and racial bias jointly contribute to the categorization of multiracial individuals. Psychological Science, 26, 1639-1645. doi: $10.1177 / 0956797615596436$ 
Jayaratne, T. E., Gelman, S. A., Feldbaum, M., Sheldon, J. P., Petty, E. M., \& Kardia, S. L. (2009). The perennial debate: Nature, nurture, or choice? Black and White Americans' explanations for individual differences. Review of General Psychology, 13, 24. doi: $10.1037 / \mathrm{a} 0014227$

Jayaratne, T. E., Ybarra, O., Sheldon, J. P., Brown, T. N., Feldbaum, M., Pfeffer, C., \& Petty, E. M. (2006). White Americans' genetic lay theories of race difference and sexual orientation: Their relationship with prejudice toward Blacks, and gay men and lesbians. Group Processes \& Intergroup Relations, 9, 77-94. doi:10.1177/1368430206059863

Johnson, C. N. (1990). If you had my brain, where would I be? Children's understanding of the brain and identity. Child Development, 61, 962-972. doi: 10.2307/1130868

Kraus, M. W., \& Keltner, D. (2013). Social class rank, essentialism, and punitive judgment. Journal of Personality and Social Psychology, 105, 247-261. doi: 10.1037/a0032895

Lane, J. D., \& Harris, P. L. (2014). Confronting, representing, and believing counterintuitive concepts: Navigating the natural and the supernatural. Perspective on Psychological Science, 9, 144-160. doi: 10.1177/1745691613518078

Medin, D. L., \& Ortony, A. (1989). Psychological essentialism. In S. Vosniadou \& A. Ortony (Eds.), Similarity and analogical reasoning (pp. 179-195). New York, NY: Cambridge University Press.

Monterosso, J., Royzman, E. B., \& Schwartz, B. (2005). Explaining away responsibility: Effects of scientific explanation on perceived culpability. Ethics \& Behavior, 15, 139-158. doi: 10.1207/s15327019eb1502_4

Rhodes, M., Leslie, S., \& Tworek, C. M. (2012). Cultural transmission of social essentialism. 
Proceedings of the National Academy of Sciences of the United States of America, 109, 13526-13531. doi: 10.1073/pnas.1208951109

Richert, R. A., \& Harris, P. L. (2006). The ghost in my body: Children's developing concept of the soul. Journal of Cognition and Culture, 6, 409-427. doi: $10.1163 / 156853706778554913$

Savani, K., Markus, H. R., Naidu, N. V. R., Kumar, S., \& Berlia, N. (2010). What counts as a choice? US Americans are more likely than Indians to construe actions as choices. Psychological Science, 21, 391-398. doi: 10.1177/0956797609359908

Schwitzgebel, E. (2011). Belief. In N. Edward (Ed.), The Stanford Encyclopedia of Philosophy. Retrieved from http://plato.stanford.edu/entries/belief/ on October 16, 2015.

Segev, M., Bergman, Y. S., \& Diesendruck, G. (2012). Is religion essential? Beliefs about religious categories. Journal of Cognition and Culture, 12, 323-337. doi: $10.1163 / 15685373-12342078$

Shtulman, A. (2008). Variation in the anthropomorphization of supernatural beings and its implications for cognitive theories of religion. Journal of Experimental Psychology: Learning, Memory, and Cognition, 34, 1123-1138. doi:10.1037/0278-7393.34.5.1123.

Sousa, P., Atran, S., \& Medin, D. (2002). Essentialism and folkbiology: Evidence from Brazil. Journal of Cognition and Culture, 2, 195-223. doi: 10.1163/15685370260225099

Taborda-Osorio, H., \& Cheries, E. W. (Under review). Infants' agent individuation: It's what's inside that counts.

Taylor, M. G. (1996). The development of children's beliefs about social and biological aspects of gender differences. Child Development, 67, 1555-1571. doi: 10.2307/1131718

Taylor, M. G., Rhodes, M. \& Gelman, S. A. (2009). Boy wills be boys, cows will be cows: 
Children's essentialist reasoning about gender categories and animal species. Child Development, 80, 461-481. doi: 10.1111/j.1467-8624.2009.01272.x

Toosi, N. R., \& Ambady, N. (2011). Ratings of essentialism for eight religious identities. International Journal for the Psychology of Religion, 21, 17-29. doi: $10.1080 / 10508619.2011 .532441$

Waxman, S., Medin, D., \& Ross, N. (2007). Folkbiological reasoning from a cross-cultural developmental perspective: Early essentialist notions are shaped by cultural beliefs. Developmental Psychology, 43, 294-308. doi: 10.1037/0012-1649.43.2.294

Williams, M. J., \& Eberhardt, J. L. (2008). Biological conceptions of race and the motivation to cross racial boundaries. Journal of Personality and Social Psychology, 94, 1022-1047. doi: 10.1037/0022-3514.94.6.1033 


\section{Appendix: Stimuli}

Note: All items were preceded by the phrase, "This person thinks that. . ." (e.g., "This person thinks that God/Ashamari can hear us/everyone when we/they pray out loud").

Religious Beliefs:

God can do miracles. [Study 1]

After people die and are buried, some of them go to heaven. [Study 1]

God knows all of our thoughts. [Studies 1 and 2]

God can hear us when we pray out loud. [Studies 1 and 2]

Ashamari knows everyone's thoughts. [Study 3]

Ashamari can hear everyone when they pray out loud. [Study 3]

Opinions:

Green is the prettiest color. [Study 1]

Oranges are the tastiest fruit. [Study 1]

Tag is the most fun game to play. [Studies 1 and 2]

Twinkle Twinkle Little Star is the best song. [Studies 1 and 2]

Spoodle is the most fun game to play. [Study 3]

Daxing the Blickets is the best song. [Study 3]

Factual Beliefs:

McDonald's sold more hamburgers than Burger King last year. [Study 2]

The Nile is the longest river in the world. [Study 2]

Klonger's sold more hamburgers than Toma last year. [Study 3]

The Grinkle River is the longest river on Tamsena. [Study 3] 